\title{
Influence of Inner Wall Profile on Descending and Melting Behavior of Burden in Blast Furnace
}

\author{
Morimasa ICHIDA, Kazuhiro NISHIHARA'), Kenji TAMURA and Masayasu SUGATA
}

Ironmaking Technology Lab., R \& D Laboratories-III, Nippon Steel Corporation, Edamitsu, Yawatahigashi-ku, Kitakyushu, Fukuoka-ken, 805 Japan. $\quad$ 1) Yawata Works, Nippon Steel Corporation, Tobihata-cho, Tobata-ku, Kitakyushu, Fukuoka-ken, 804 Japan.

(Received on October 8, 1990; accepted in the final form on February 22, 1991)

\begin{abstract}
The influences of the inner wall profile and ore/coke distribution on the descending and melting behaviors of burden were analyzed by using a three-dimensional semicircular warm model of the blast furnace under conditions set as similar as possible to the physical phenomena in the furnace. It is confirmed that in the case of a profile with blocks installed on the belly where the horizontal stress acting to wall is at its maximum, a sluggishly descending zone of a thickness $2-5$ times of the projecting length of the blocks is formed near the wall just above the blocks. It is estimated that the thickness of sluggishly descending zone near the wall increases with increasing projecting length of the blocks on the wall and with decreasing installation interval of distance between the blocks and it decreases with increasing ore/coke near the wall. It is estimated that the height of the dead man decreases with the formation of the wall sluggishly descending zone due to the blocks on the wall. For decreasing the thickness of the sluggishly descending zone near the wall, the ore/coke near the wall should preferably be increased as far as the heat-flow ratio is permitted. Such a burden distribution is effective for pulverized coal injection operation in which the melting capacity near the wall is large.
\end{abstract}

KEY WORDS: ironmaking process; blast furnace; warm model; inner wall profile; ore/coke; sluggishly descending zone; dead man; all coke operation; pulverized coal injection operation.

\section{Introduction}

To stabilize blast furnace operation, it is important to expand the burden descending region (between the wall and the dead man) in the lower part of the furnace and secure the smooth descent of burden. In order to do so, it is necessary to prevent the formation of a sluggishly descending zone and scaffolds on the inner wall of the furnace and make the dead man as small as possible. But the inner wall profile is damaged with the lapse of the operating time of blast furnace and $\Gamma$ staves and tips of cooling plates are exposed. In this case, sluggishly descending zones and scaffolds are formed and they influence the burden descending velocity distribution and the burden distribution at the top level, therefore, they decrease the control ability of the blast furnace.

Until now, studies ${ }^{1-7)}$ based on cold model experiments were reported on the relation between the descending behavior near the wall and the inner wall profile of the blast furnace. But many studies are based on the two-dimensional model experiments ${ }^{1-5}$ ) and the three-dimensional cold model experiments. ${ }^{6,7)}$ In the two-dimensional model, it is difficult to simulate the burden descending behavior in the center and the formation behavior of dead man, because the wall effect is large. In the three-dimensional cold model, it is difficult to simulate the change of the descending velocity due to burden softening and melting, because the burden does not melt.

The authors, therefore, analyzed the influences of the inner wall profile in the lower part of the furnace, where the burden stress at wall was large and the temperature was high, by charging quasi-ore of low melting point and coke to a three-dimensional semicircular warm model of the blast furnace under conditions set as similar as possible to the physical phenomena like the descending and melting behaviors of burden in the furnace, not to chemical phenomena like chemical reaction in the furnace. Simulteneously with an analysis of the influences of the ore to coke ratio distribution on the profile of the sluggishly descending zone near the wall and the profile of the dead man, optimum burden distribution in a blast furnace with the wall broken profile was discussed.

\section{Experimental Method and Conditions}

The $1 / 20$ scale three-dimensional semicircular model of blast furnace described in the previous report ${ }^{8,10}$ was used as the experimental apparatus. The same coke and quasi-ore in the previous report ${ }^{8,10)}$ were used as the burden materials. The standard experiment conditions were also the same as those described in the previous report. ${ }^{8,10}$ )

Five profiles shown in Fig. 1 were used as the inner wall profiles of the blast furnace. (1) is an normal profile assuming the conditions soon after blowing-in (shaft angle: $81^{\circ} 04^{\prime}$, bosh angle: $81^{\circ} 07^{\prime}$, belly height: $150 \mathrm{~mm}$, bosh height: $200 \mathrm{~mm}$ ). (2) and (3) are profiles with blocks of a projecting length of $15 \mathrm{~mm}$ installed on the bosh bottom and belly bottom assuming 
scaffolds and $\Gamma$ type staves on the wall. (4) is a profile with blocks of projecting lengths of 10 and $15 \mathrm{~mm}$ installed on the lower part of the shaft, on the belly top and on the belly bottom assuming $\Gamma$ type staves. (5) is a profile with blocks of a projecting length of $10 \mathrm{~mm}$ installed on the region from the lower part of the shaft to the bosh (installation interval of distance: $30 \mathrm{~mm}$ in the belly and bosh, $60 \mathrm{~mm}$ in the lower part of the shaft) assuming the exposure of cooling plates.

For the charging conditions were selected three charging patterns (movable armors (MA) not yet used $\left(\mathrm{C}_{0} \mathrm{O}_{0}\right)$, charging of ore closer to the furnace center $\left(\mathrm{C}_{0} \mathrm{O}_{20}\right)$ and charging of coke closer to the furnace center $\left(\mathrm{C}_{20} \mathrm{O}_{0}\right)$ : herein called the " charging of ore farther from the furnace center"), as described in the previous report. ${ }^{8,10)}$ The suffix used in each pattern is the angle of the plate of the MA with the vertical plane. When the MA was not yet used, the layer thickness ratio of quasi-ore to coke $\left(L_{o} / L_{c}\right.$, herein called the "ore/coke") in the radial direction is distributed nearly uniformly. In the case of the charging of ore closer to the furnace center, the ore/coke in the intermediate region is at its maximum, while in the case of the charging of ore farther from the furnace center, the ore/coke in the wall region is at its maximum.

\section{Experimental Results and Discussion}

\subsection{Influences of Wall Blocks in the Lower Part of the Furnace on the Descending and Melting Behaviors of Burden}

Figs. 2 and 3 show the influences of wall blocks on the packed conditions of burden in the furnace and the retention time (time line) in the case of the nonuse

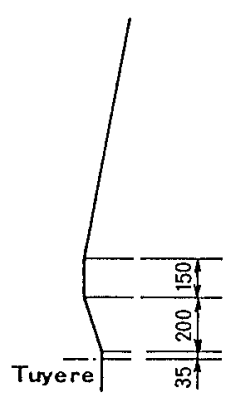

(1) No block (Normal profile)

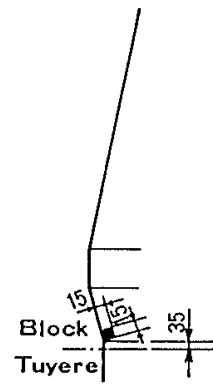

(2) Block on bosh botloin

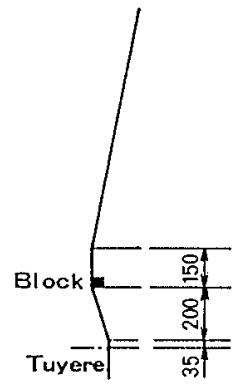

(3) Block on belly bot toill

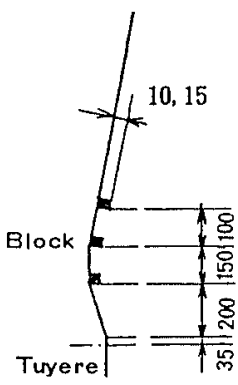

(4) Blocks on shaft and belly

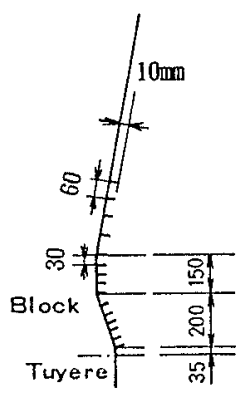

(5) Blocks on shaft belly and bosh

Fig. 1. Inner wall conditions.

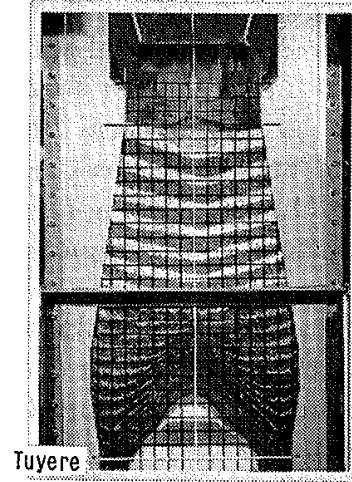

(1) No block

(Normal profile)

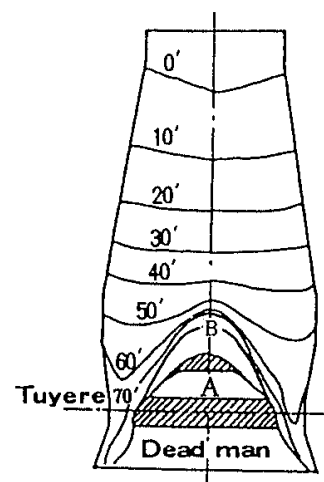

(1) No block

(Normal profile)

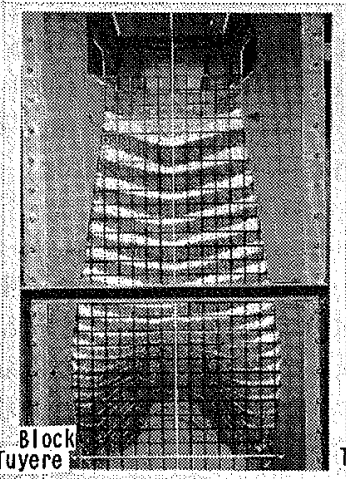

(2) Block on bosh bottom

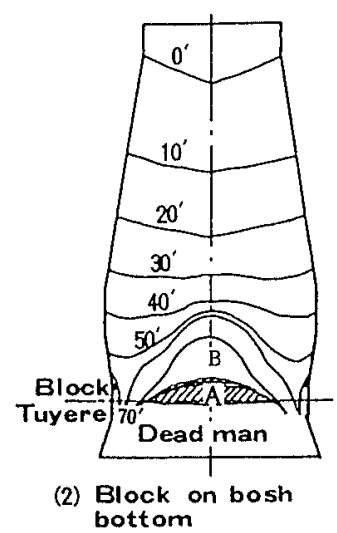

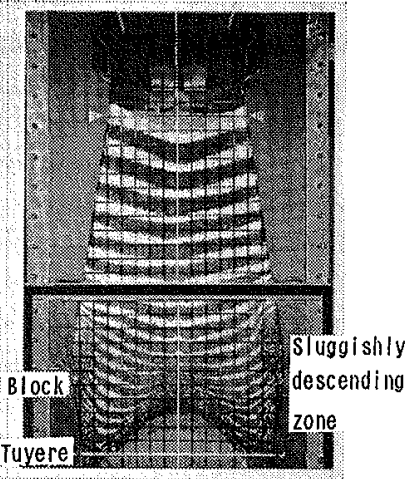

(3) Block on belly bottom

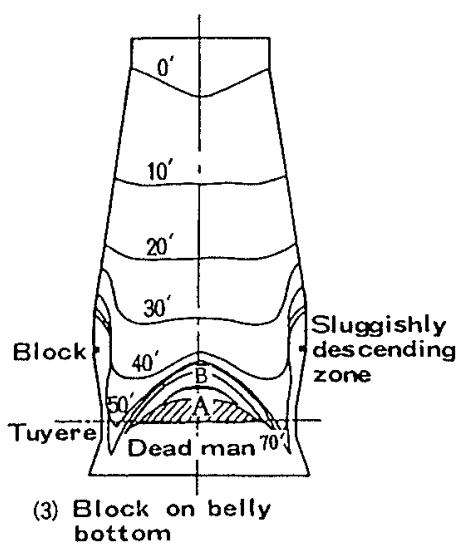

Fig. 2.

Influence of block position on cohesive zone profile and dead man profile in case of $\left(C_{0} O_{0}\right)$ charging pattern.
Dead man:

Region defined by the isochronal line at the time of $70 \mathrm{~min}$

Dead zone A+Sluggishly descending zone $\mathrm{B}$

Fig. 3.

Influence of block position on burden descending in case of $\left(C_{0} O_{0}\right)$ charging pattern. 
of the MA in which the radial ore/coke distribution is nearly uniform. In the case of the normal profile, the descending velocity distribution of burden in the shaft was nearly uniform in the radial direction, but the descending velocity in the center region decreased from the upper end of the belly. The dead man was formed in the region from the middle stage of the belly, and an inverted V-shaped cohesive zone was formed. In the case of the profile with blocks installed on the bosh bottom, a small sluggishly descending zone was formed near the wall just above the blocks, the dead man somewhat contracted without much influencing the descending behavior of burden and an inverted V-shaped cohesive zone was formed. In the case of the profile with blocks installed on the belly bottom, a sluggishly descending zone of a thickness 2-5 times the projecting length of the blocks was formed near the wall just above the blocks, the dead man contracted and a W-shaped cohesive zone was formed.

\subsection{Influence of Wall Blocks and Ore/Coke Distribution on the Formation Behavior of Wall Sluggishly Descend- ing Zone}

Fig. 4 shows the influences of the projecting length of wall blocks, installation interval of distance between wall blocks, and wall block position on the thickness of the wall sluggishly descending zone. The thickness of the wall sluggishly descending zone was determined by the isochronal line at the time of 70 min of colored coke charged as tracer after starting the experiment.

In the case of a profile with blocks installed on the bosh bottom, the thickness of the wall sluggishly descending zone is less than 2 times the projecting length of the wall blocks. In the case of a profile with

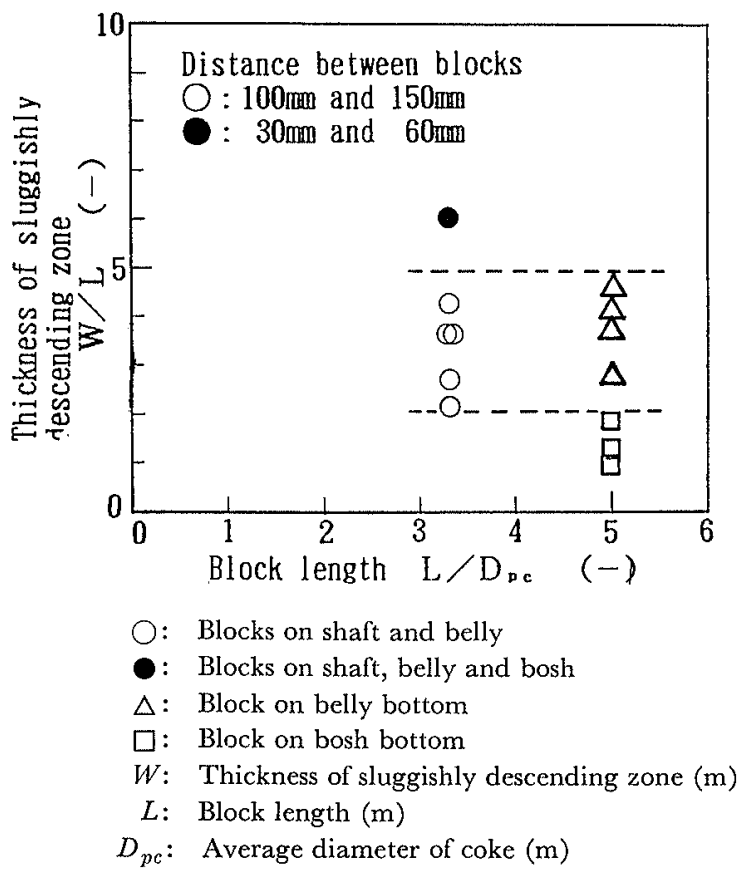

Fig. 4. Influences of block length, distance between blocks and block position on thickness of sluggishly descending zone. blocks installed on the belly bottom, however, the thickness of the wall sluggishly descending zone is $2-5$ times the projecting length of the wall blocks. This fact suggests that a thickness of the wall sluggishly descending zone increases when the inner wall profile soon after blowing-in is damaged and $\Gamma$-type staves and cooling plates are exposed. The thickness of the wall sluggishly descending zone differs according to the installation interval of distance between the blocks. The thickness of the wall sluggishly descending zone formed in the case of a profile with blocks installed at short intervals of $30 \mathrm{~mm}$ assuming the cooling-platetype blast furnace is nearly twice the thickness of the wall sluggishly descending zone formed in the case of a profile with blocks installed at intervals of 100 and $150 \mathrm{~mm}$ on the wall in the lower part of the furnace assuming the stave-type blast furnace. This fact suggests that the wall sluggishly descending zone is easier to be formed and more difficult to be dropped in cooling-plate-type blast furnace than in stave-type blast furnace.

Fig. 5 shows the influences of the ore/coke near the wall (within $22.5 \mathrm{~mm}$ ( $450 \mathrm{~mm}$ in the value converted into that of the actual blast furnace) from the wall) and wall block position on the thickness of the wall sluggishly descending zone. When the ore/coke near the wall is high, namely when the vertical loads on the blocks are large, the thickness of the wall sluggishly descending zone decreases. The mechanism of the decrease in the thickness with the increase in the ore/coke is uncertain. However, this fact suggests the possibility that the thickness of the wall sluggishly descending zone can be controlled by the ore/coke near the wall.

Fig. 6 shows an example of experiment conducted by increasing the ore/coke near the wall in the course of the experiment in order to decrease the thickness of the wall sluggishly descending zone formed near the wall just above the blocks in the case of the profile

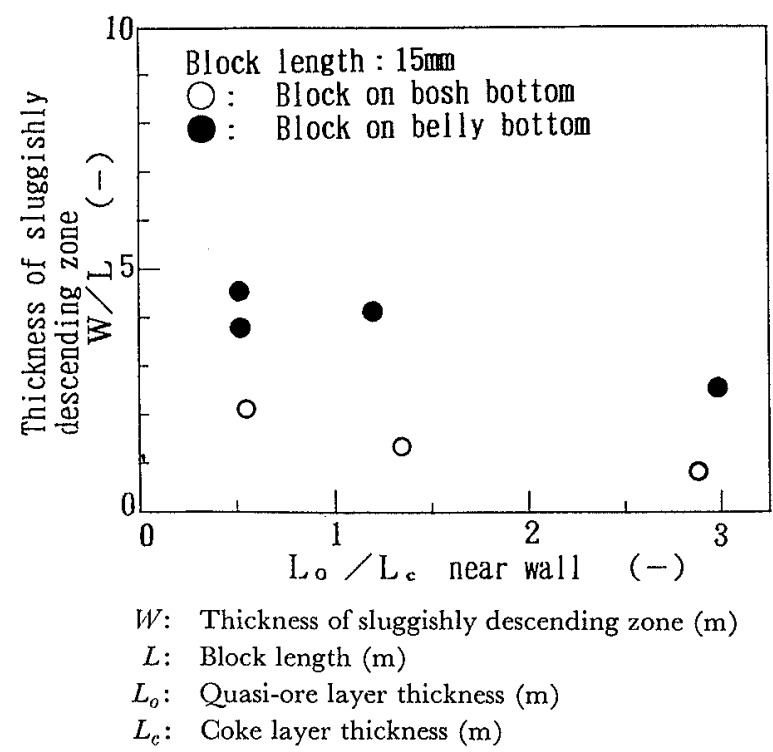

Fig. 5. Influences of $L_{o} / L_{c}$ near wall (within $22.5 \mathrm{~mm}$ from wall) and block position on thickness of sluggishly descending zone. 


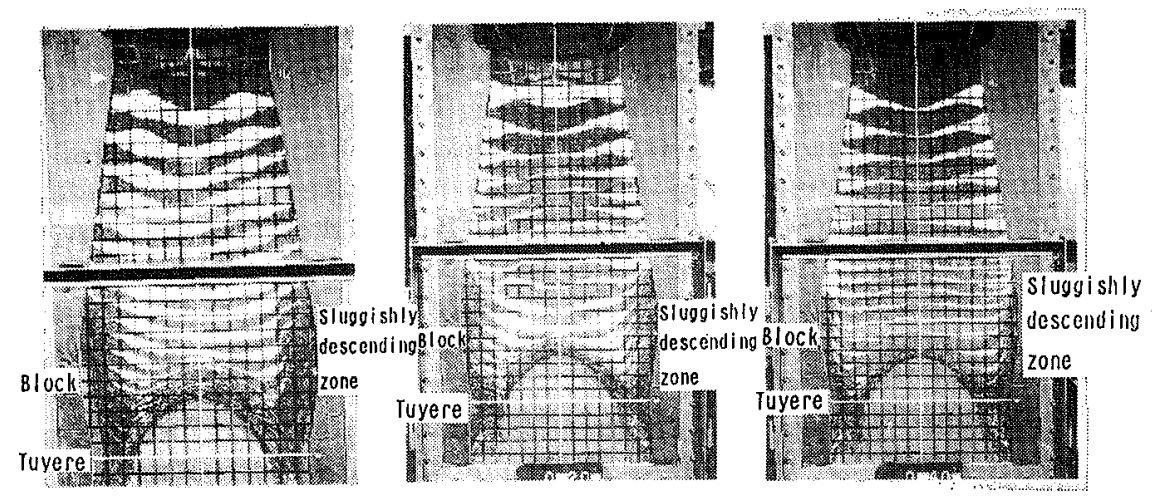

(1) Charging pattern $\left(\mathrm{C}_{0} \mathrm{O}_{20}\right)$
(3) 40 min after change of charging pattern from $\left(\mathrm{C}_{0} \mathrm{O}_{20}\right)$ to $\left(\mathrm{C}_{20} \mathrm{O}_{0}\right)$
(2) 20 min after change of Charging pattern from $\left(\mathrm{C}_{0} \mathrm{O}_{20}\right)$ to $\left(\mathrm{C}_{20} \mathrm{O}_{0}\right)$
Fig. 6.

Decrease in the thickness of sluggishly descending zone by changing the charging pattern from $\left(C_{0} O_{20}\right)$ to $\left(C_{20} O_{0}\right)$.

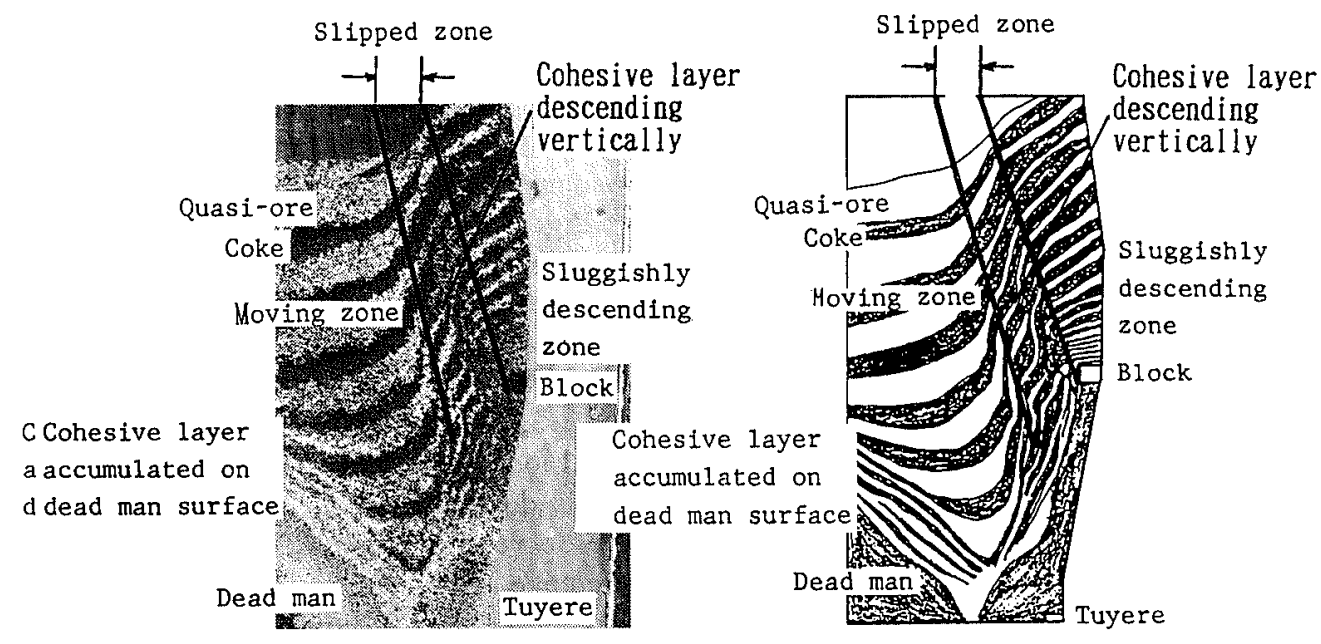

Fig. 7. Layer structure of sluggishly descending zone near wall.

with blocks installed on the belly bottom. After changing from the charging of ore closer to the furnace center $\left(\mathrm{C}_{0} \mathrm{O}_{20}\right)$ to the charging of ore farther from the furnace center $\left(C_{20} O_{0}\right)$ to increase the ore/coke near the wall, the thickness of the sluggishly descending zone formed near the wall just above the blocks greately descreased.

\subsection{Layer Structure and Formation Mechanism of Wall Sluggishly Descending Zone}

Fig. 7 shows the layer structure of the wall sluggishly descending zone which is formed in the case of the profile with blocks installed on the belly bottom. The wall sluggishly descending zone has an accumulated layer structure consisting of cohesive layers of quasi-ore and coke layers. The cohesive layers of quasi-ore are considered to have been formed because the descending velocity of burden near the wall decreased due to the existence of the blocks. On the boundary between the wall sluggishly descending zone and the moving bed there is a shear zone in which burden always descends being subjected to shear stress. In this shear zone, the cohesive layers descend longitudinally and the coke descends with slipping. Therefore, the void fraction in the shear zone is estimated to be larger than that in the moving bed.

Fig. 8 shows the influence of the installation position of blocks on the burden stress distribution at the
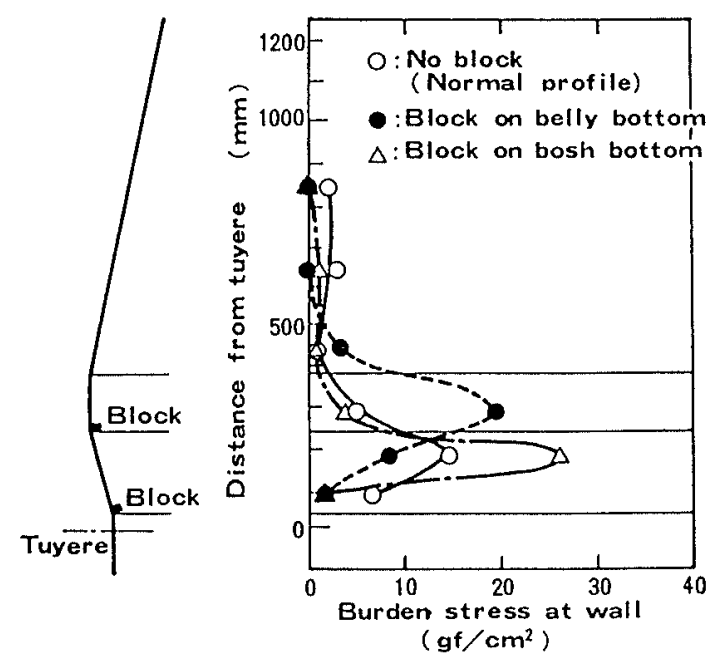

Fig. 8. Influence of block position on burden stress at wall.

wall. In the case of the profile with blocks installed on the bosh bottom, the burden stress at the wall becomes maximum in the middle part of the bosh. However, since the value of burden stress at the wall in the lower part of the bosh just above the blocks is small, the frictional force at the wall in that part is small. Therefore, the sluggishly descending zone near the wall just above the blocks becomes small. In the case of the profile with blocks installed on the belly 
bottom, on the other hand, the range of increase in the burden stress at the wall is wide. And, since the burden stress at the wall becomes maximum in the belly just above the blocks, the frictional force in that part is large. Therefore, the sluggishly descending zone formed near the wall just above the blocks becomes large.

\subsection{Influences of Wall Blocks and Ore/Coke Distribution on the Formation Behavior of Dead Man}

Fig. 9 shows the influences of wall blocks and the ore/coke in the center region (within a radius of 50 $\mathrm{mm}$ ( $1000 \mathrm{~mm}$ in the value converted into that of the actual blast furnace) from the furnace center) on the dead man height. The height of the dead man, like the thickness of the wall sluggishly descending zone, was determined by the isochronal line at the time of 70 min of colored coke charged as tracer after starting the experiment. The height of the dead man greatly decreased according to the installation of the blocks. In the case of the profile with blocks installed on the belly bottom, the height was smallest. Also, the height of the dead man decreased with increasing ore/coke in the center region (within a radius of 50 $\mathrm{mm}$ ( $1000 \mathrm{~mm}$ in the value converted into that of

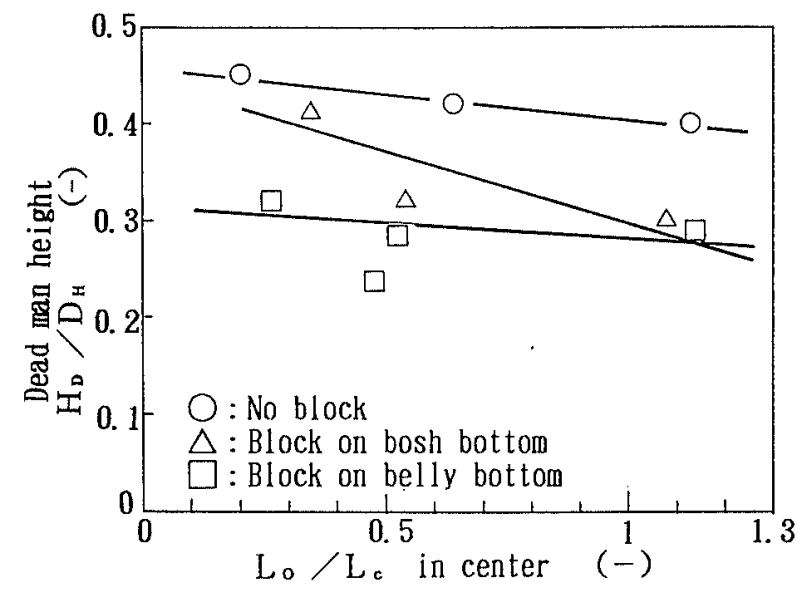

$H_{D}$ : Deadman height $(\mathrm{m})$

$D_{H}$ : Hearth diameter $(\mathrm{m})$

$L_{0}$ : Quasi-ore layer thickness $(\mathrm{m})$

$L_{c}$ : Coke layer thickness $(\mathrm{m})$

Fig. 9. Influences of $L_{o} / L_{c}$ in center (within $50 \mathrm{~mm}$ from center) and block position on dead man height. actual blast furnace) from the center).

The changes in the height of the dead man described above are closely related to the formation behavior of the wall sluggishly descending zone. In the case of the profile with blocks installed on a belly bottom, the dead man is estimated to have become small because the sluggishly descending zone was formed near the wall just above the blocks and the region of burden descending in the lower part of the furnace moved toward the dead man. As described in the previous report, ${ }^{10)}$ even in the case in which the wall sluggishly descending zone is not formed, as the ore/coke in the center region increased, the dead man became small and the descending velocity in the center region and the intermediate regions increased.

\subsection{Influence of Wall Blocks on Temperature Distribution in the Furnace}

Fig. 10 shows the relation between the temperature distribution in the lower part of the furnace measured by infrared radiation thermometer and wall block position in the case of charging the burden materials without using the MA in which the radial ore/coke distribution is nearly uniform.

In the case of the normal profile, the region surrounded by the inverted $V$-shaped cohesive zone and the dead man with the tuyere as its center was the high-temperature region. In the case of the profile with blocks installed on the bosh bottom, the temperature near the wall somewhat increased, while the temperature of the dead man somewhat decreased, though the temperature distribution pattern in the lower part of the furnace was nearly the same as that in the case of the normal profile. In the case of the profile with blocks installed on the belly bottom, the temperature distribution in the lower part of the furnace was greatly different from those of the above two profiles. The temperature near the wall increased, while the temperature of the dead man considerably decreased.

\subsubsection{Influence of Wall Blocks on the Descending Velocity Distribution of Burden}

Fig. 11 shows the relation between the relative descending velocity $\left(V / V_{\text {ave. }}\right)$ distribution of burden in the radial direction defined in the previous report ${ }^{9,10)}$ and the installation position of wall blocks, in which

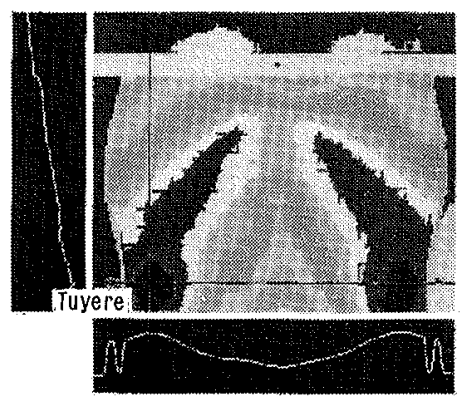

(1) No block (Normal profile)

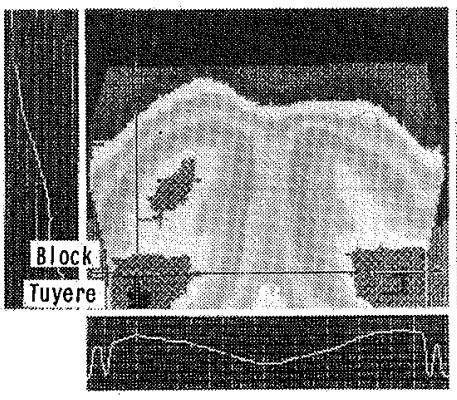

(2) Block on bosh bottom

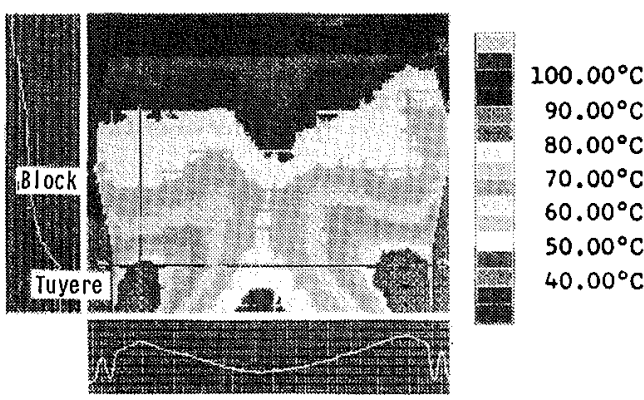

(3) Block on belly bottom

Fig. 10. Relation between block position and temperature distribution in the lower part of blast furnace model in case of $\left(\mathrm{C}_{0} \mathrm{O}_{0}\right)$ charging pattern. 
the burden materials were charged without using the MA and the radial ore/coke distribution was nearly uniform. The radial descending velocity distribution in the case of the profile with blocks installed on the bosh bottom was almost the same as that in the case of the normal profile. But the radial descending ve-

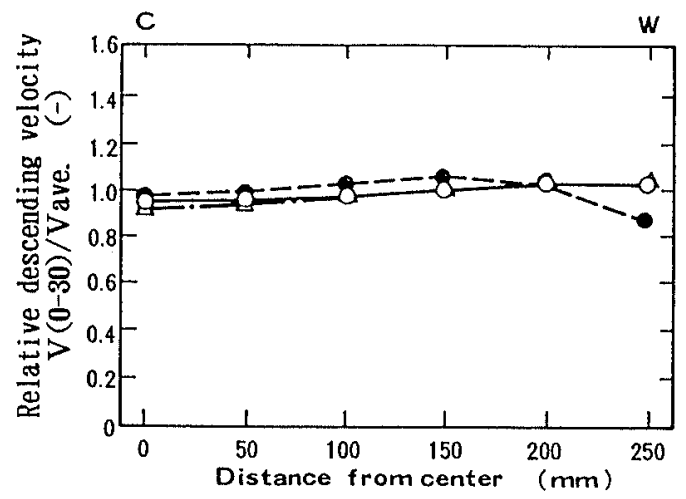

(1) Shaft zone

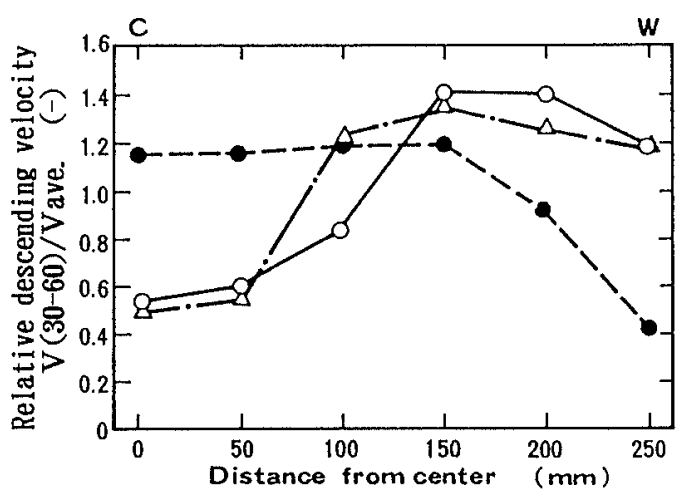

(2) Belly and bosh zones

O: No blcok (Normal profile)

- Block on belly bottom

$\triangle$ : Block on bosh bottom

Fig. 11. Relation between block position and radial distribution of relative burden descending velocity $\left(V / V_{\text {ave. }}\right)$ in case of $\left(C_{0} O_{0}\right)$ charging pattern. locity distribution in the case of the profile with blocks installed on the belly bottom was greately different from those of the above two profiles in the lower part of the furnace. The descending velocity in the wall region was low, while that in the center region was high.

Fig. 12 compares the calculated values with the experimental values of descending velocity in the cases of the nomal profile and the profile with blocks installed on the belly bottom, based on Sugiyama et al.'s model ${ }^{12,13)}$ assuming the potential flow. The experimental values of descending velocity distribution are obtained by the same method as described in the previous report.9,10) In calculating assuming the potential flow, experimental values were used for the shapes of the coke layer, ore layer, cohesive zone, wall sluggishly descending zone and the dead man, and it was also assumed that the dead man and wall sluggishly descending zone have considerably large flow resistance.

The calculated values and experimental values of descending velocity distribution showed relatively good correspondence and it was proved that the radial descending velocity distribution might be estimated accurately by setting a parameter of flow resistance in the equation for the potential flow movement.

\subsubsection{Influence of Wall Blocks on Gas Flow}

Gas flow lines were calculated using Sugiyama et al.'s mathematical model of gas flow. ${ }^{12,13)}$ In this calculation, as shown in Table 1 , the void fraction of the wall sluggishly descending zone was assumed to be equal to that of the cohesive zone because the wall sluggishly descending zone consists of the cohesive layers of quasi-ore and coke layers and the void fraction of the shear zone was assumed to be equal to that of coke layer because in the shear zone the coke descends with slipping. In calculating the gas flow lines, experimental values were used for the shapes of the coke layer, ore layer, cohesive zone, wall sluggishly
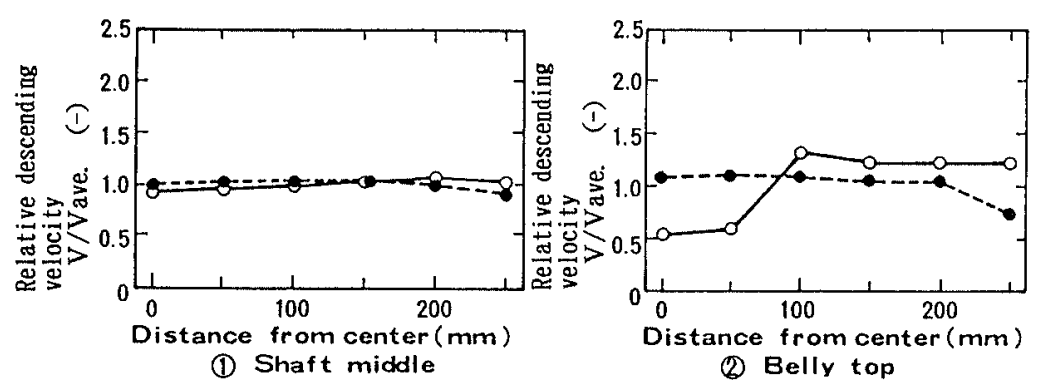

(2) Belly top

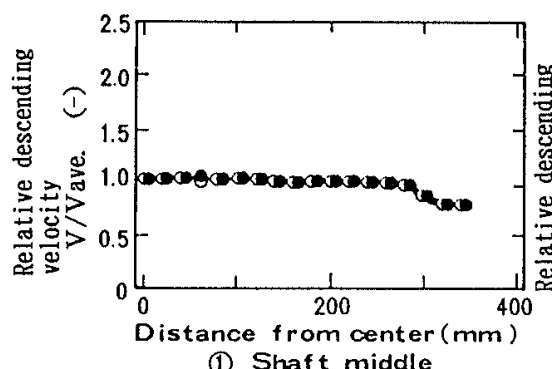

(1) Shaft middle

(2) Calculated results

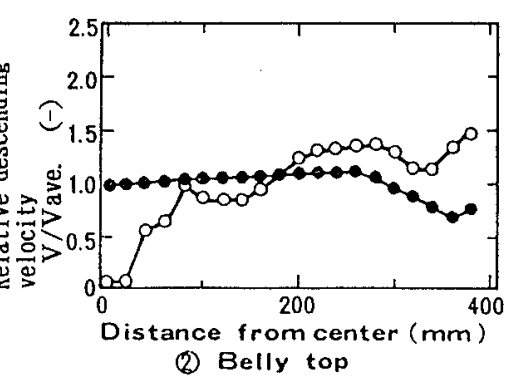

(6) Belly top
O: No block (Normal profile)

: Block on belly bottom

Fig. 12.

Comparison between calculated results and experimental results on radial distribution of burden descending. 
descending zone and dead man.

Fig. 13 shows the results of calculation of gas flow lines in the case of the charging of ore closer to the furnace center, in which the ore/coke in the intermediate region becomes maximum, for both the normal profile and the profile with blocks installed on the belly bottom. In the case of the normal profile, in which a W-shaped cohesive zone was formed, a part of the gas from the tuyere flowed out along the wall into the lump zone. In the case of the profile with blocks installed on the belly bottom, in which a Ushaped cohesive zone was formed, the gas flow rate in the shear zone between the wall sluggishly descending zone and the moving bed was large, while the gas flow rate in the dead man was small, as can be understood from the fact that the space between the flow lines in the shear zone is narrow, while the space between the gas flow lines in the dead man is wide.

\subsubsection{Influence of Wall Blocks on Temperature Dis-} tribution in the Lower Part of the Furnace

In the case of the profile with blocks installed on the belly bottom, the temperature distribution in the lower part of the furnace was greatly different from those of the normal profile as shown in Fig. 10. The temperature near the wall increased and the tempera-

Table 1. Assumption for calculation.

(1) Shapes of $\left\{\begin{array}{l}\text { quasi-ore layer } \\ \text { coke layer } \\ \text { cohesive zone } \\ \text { dead man } \\ \text { sluggishly descending zone } \\ \text { slipped zone }\end{array}\right.$

(Shapes of these are the same as experimental data.)

(2) Void frac- \begin{tabular}{cl} 
tion of \\
coke layer & $\left(\varepsilon_{\text {coke }}\right)=0.51^{10)}$ \\
cohesive zone & $\left(\varepsilon_{\text {cohesive zone }}\right)=0.7 * \varepsilon_{\text {ore }}{ }^{14)}$ \\
dead man & $\left(\varepsilon_{\text {dead man }}\right)=0.9 * \varepsilon_{\text {coke }}{ }^{10)}$ \\
receway & $\left(\varepsilon_{\text {raceway }}\right)=1.4 * \varepsilon_{\text {coke }} \mathrm{e}^{15)}$ \\
sluggishly de- & $\left(\varepsilon_{\text {sdz }}\right)=\varepsilon_{\text {cohesive zone }}$ \\
scending zone & \\
slipped zone & $\left(\varepsilon_{\text {slipped zone }}\right)=\varepsilon_{\text {coke }}$ \\
\hline
\end{tabular}

ture of dead man decreased. The reason of decrease in the temperature of dead man is considered as the following. As can be understood from the knowledge described in Secs. 3.5.1 and 3.5.2, in the case of the profile with blocks installed on the belly bottom, the descending velocity decreased and the gas flow velocity increased in the wall region, while the descending velocity increased and the gas flow velocity decreased in the center region. As a result, the heat-flow ratio in the center region greatly increased, and the temperature of dead man decreased.

Fig. 14 compares calculated values based on Sugiyama et al.' model ${ }^{12,13)}$ which was prepared considering the gas flow, solid flow and heat transfer, with experimental values of temperature distribution in the lower part of the furnace in the case of the profile with blocks installed on the belly bottom. The experimental values of temperature distribution in the furnace are values measured by infrared radiation thermometer.

The calculated values and experimental values of temperature distribution in the lower part of the furnace show good correspondence in pattern.

\section{Optimum Burden Distribution Based on Knowledge Obtained from the Blast Fur- nace Three-dimensional Semicircular Model Experiment}

Based on the knowledge obtained from the blast furnace three-dimensional semicircular model experiment described in Chap. 3, optimum burden distribution in a blast furnace with the wall broken profile in the intermediate stage and the subsequent stage of the furnace operation was considered.

In the case of the profile with the wall broken in the lower part of the furnace, the charging of ore closer to the furnace center has the possibility to form the wall sluggishly descending zone and to contract the dead man. As the result, the radial descending velocity distribution and heat-flow ratio distribution are liable to become not uniform and the dead man temperature is liable to decrease. Therefore, it is necessary to have a correct grasp of change of the
Fig. 13.

Comparison of gas stream lines in case of normal profile and profile with block on belly bottom.

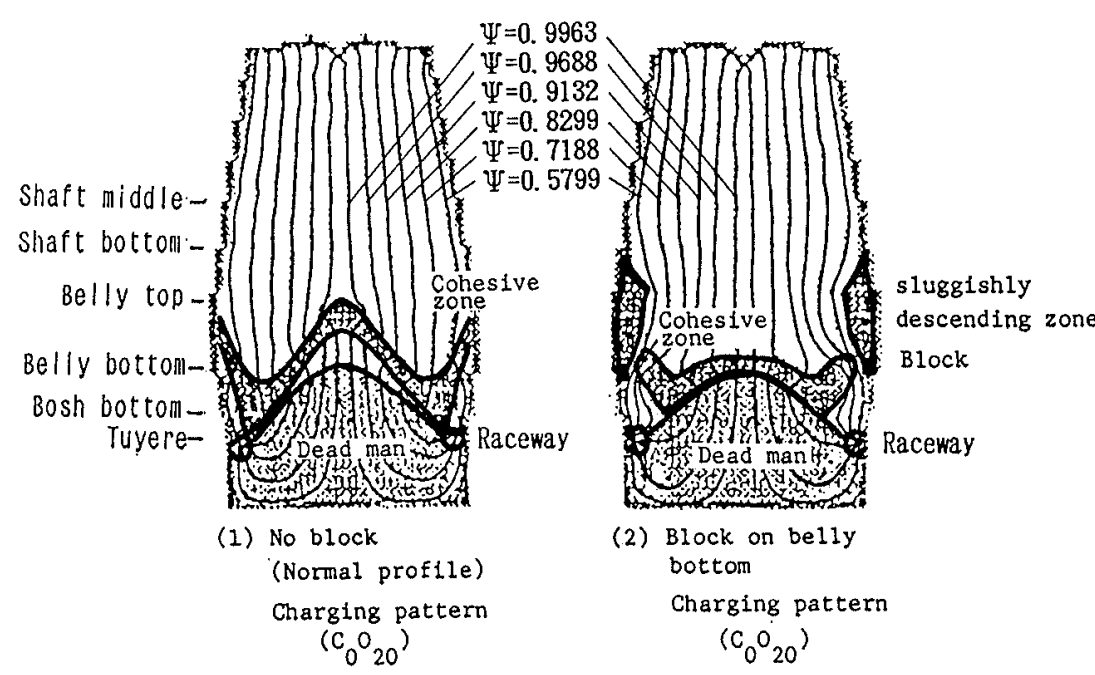




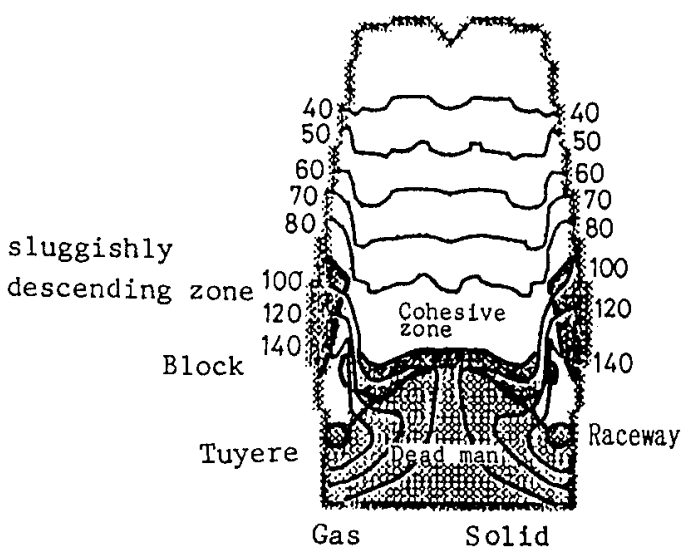

(1) Calculated result

Block on belly bottom Charging pattern $\left(\mathrm{C}_{0} \mathrm{O}_{20}\right)$

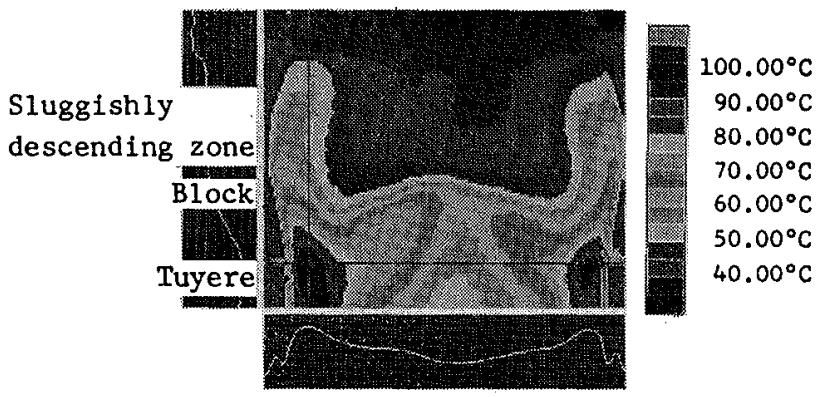

(2) experimental result Block on belly bottom Charging pattern $\left(\mathrm{C}_{0} \mathrm{O}_{20}\right)$

Fig. 14. Comparison between calculated result and experimental result on temperature patterns.

inner wall profile of the furnace with time and to determine a optimum burden distribution.

On the other hand, it is effective as a means of decreasing the thickness of the wall sluggishly descending zone to increase the ore/coke near the wall by the charging of ore farther from the furnace center, as described in Sec. 3.2. In that case, however, the lower part of the furnace is liable to become inactive because this charging pattern increases the heat-flow ratio near the wall and decreases the wall temperature in the lower part of the furnace and the temperature near the raceway. ${ }^{10,11)}$ Therefore, the increase of the ore/coke near the wall by the charging of ore farther from the furnace center is a difficult burden distribution at the all coke operation in which the wall temperature tends to decrease, but it is an effective burden distribution at the pulverized coal injection operation in which the melting capacity near the wall is large.

\section{Conclusion}

The influences of the inner wall profile and ore/ coke distribution on the descending and melting behaviors of burden were analyzed by using a threedimensional semicircular model of the blast furnace under conditions set as similar as possible to the physical phenomena in the furnace, and the following knowledge was obtained.

(1) In the case of a profile with blocks installed on the belly bottom, the descending behavior of burden is greatly different from that in the case of the normal profile. A sluggishly descending zone of a thickness 2-5 times the projecting length of the blocks is formed near the wall just above the blocks and the temperature of the dead man decreases.

(2) The wall sluggishly descending zone consists of accumulated cohesive layers of quasi-ore and coke layers, and in the shear zone on the boundary between the wall sluggishly descending zone and the moving bed, the cohesive layers descend longitudinal- ly and the coke descends with slipping.

(3) The wall sluggishly descending zone is liable to be formed in the belly because the horizontal stress at the wall becomes maximum in the belly.

(4) The thickness of the wall sluggishly descending zone increases with increasing projecting length of the wall blocks and with decreasing installation interval of distance between the blocks and it decreases with increasing ore/coke near the wall (within 22.5 $\mathrm{mm}$ ( $450 \mathrm{~mm}$ in the value converted into that of the actual blast furnace) from the wall).

(5) The height of the dead man decreases with the formation of the wall sluggishly descending zone due to the wall blocks and with increasing ore/coke in the center region (within a radius of $50 \mathrm{~mm}$ ( 1000 $\mathrm{mm}$ in the value converted into that of the actual blast furnace) from the furnace center).

(6) In the case of a profile with the wall broken in the lower part of the furnace and blocks existing near the wall, the ore/coke near the wall should preferably be increased, as the heat-flow ratio is permitted. Such a burden distribution is effective particularly for pulverized coal injection operation in which the melting capacity near the wall is large.

\section{REFERENCES}

1) N. Inagaki, M. Tokunaga, Y. Nomiya and M. Matsuda: Tetsu-to-Hagané, 67 (1981), S23; Trans. Iron Steel Inst. Jpn., 21 (1981), B423.

2) M. Ichida and H. Biausser: Tetsu-to-Hagané, 69 (1983), S61; Trans. Iron Steel Inst. Jpn., 23 (1983), B238.

3) Y. Oono and K. Kondo: Tetsu-to-Hagané, 70 (1984), S51.

4) Y. Sato, T. Sugiyama, M. Nakamura and Y. Hara: Tetsuto-Hagané, 66 (1980), S634; Trans. Iron Steel Inst. Jpn., 21 (1981), B50.

5) M. Ichida, K. Tamura, Y. Hayashi and M. Sugata: Ironmaking Conf. Proc., Vol. 47, ISS-AIME, Warrendale, PA, (1988), 555.

6) M. Shimizu, A. Yamaguchi, S. Inaba and K. Narita: Tetsu-to-Hagané, 68 (1982), 936.

7) M. Shimizu, Y. Kimura, M. Isobe, C. Che and S. Inaba: Tetsu-to-Hagané, 73 (1987), 1996. 
8) M. Ichida, K. Tamura and Y. Hayashi: CAMP-ISIJ, 1 (1988), 1071.

9) M. Ichida, K. Tamura, Y. Hayashi and K. Nishihara: CAMP-ISIJ, 2 (1989), 70.

10) M. Ichida, K. Nishihara, K. Tamura, M. Sugata and H. Ono: ISIJ Int., 31 (1991), 505.

11) M. Ichida, K. Tamura, Y. Hayashi and K. Nishihara: CAMP-ISIJ, 2 (1989), 71.

12) T. Sugiyama and M. Sugata: Seitetsu Kenkyu, (1987), No.
325,34 .

13) T. Sugiyama, Y. Hayashi, M. Sugata, H. Shibaike and N. Suzuki: CAMP-ISIJ, 1 (1988), 23.

14) M. Gono, T. Noda, Y. Shimomura, T. Sugiyama and H. Sato: The 54th Comm. (Ironmaking), Japan Soc. for the Promotion of Sci. (JSPS), Rep. No. 1663 (Nov. 1983).

15) M. Nakamura, T. Sugiyama, T. Uno, Y. Hara and S. Kondo: Tetsu-to-Hagané, 63 (1977), 28. 